\title{
ANNUAL CHANGES IN THE SEXUAL POTENCY OF CAPTIVE MALE RHESUS MONKEYS
}

\author{
RICHARD P. MICHAEL, D. ZUMPE, T. M. PLANT AND R. G. EVANS \\ Department of Psychiatry, Emory University School of Medicine, \\ Atlanta, Georgia 30322, and \\ Georgia Mental Health Institute, Atlanta, Georgia 30306, U.S.A.
}

(Received 10th February 1975)

Like many non-primate mammals, several non-human primates have wellmarked mating and birth seasons (Lancaster \& Lee, 1965; Michael \& Zumpe, 1971). In a relatively controlled laboratory environment, Michael \& Keverne (1971) found that intact rhesus males paired with intact females, whose oviducts had been ligated to prevent pregnancy, showed a peak in ejaculatory activity in December followed by a decline between February and May. The timing of the long-term changes in potency of these laboratory males was, therefore, very similar to that occurring in the natural habitat in North India (Southwick et al., 1965; Michael \& Wilson, 1975). This suggests the existence of an annual behavioural rhythm that is to some extent independent of major environmental variables. A clearcut annual rhythm in the plasma testosterone of rhesus males maintained in the laboratory has now been demonstrated (Plant et al., 1974), and this raises the question of whether or not the annual changes in plasma testosterone play any causative role in determining the annual behavioural rhythms.

To clarify this matter, eight intact male rhesus monkeys (weighing 7.6 to $12.3 \mathrm{~kg}$ ) were studied over a period of 13 months (December 1972 to December 1973) during 2183 tests carried out in Atlanta. Each male was paired with four ovariectomized females (weighing 4.6 to $6.5 \mathrm{~kg}$ ), making 32 paired combinations. Animals were obtained from North India, quarantined in London for 4 to 10 months, and shipped to Atlanta 2 to 3 months before the start of the study. Animals were housed in individual cages together in the same animal room from which natural daylight was completely excluded. Artificial lighting was rigorously controlled giving a 14-hr day between 06.15 and 20.15 hours. Temperature was maintained by air conditioning between 68 and $74^{\circ} \mathrm{F}$. Free access to food and water was allowed. Five months before testing started, females were ovariectomized, and thereafter received subcutaneous injections of $10 \mu \mathrm{g}$ oestradiol monobenzoate/day throughout the study. Behavioural tests were conducted from behind one-way vision mirrors in special observation cages to which first the male and then the female of the pair was introduced (Michael et al., 1968). The duration of tests was $1 \mathrm{hr}$, and each male was tested on consecutive days with each female so that males were tested once and females twice daily 5 days a week. The order in which animals were tested was 
kept constant. Particular attention was given to the mean numbers of ejaculations/test as a direct measure of male sexual potency. After previous adaptation to the procedure, weekly blood samples were obtained at 08.00 hours from the saphenous veins of the untranquillized males, and plasma testosterone was estimated by radioimmunoassay without chromatography; the assay therefore additionally estimated dihydrotestosterone which comprised $<9 \%$ of the total plasma androgen (Michael et al., 1974).

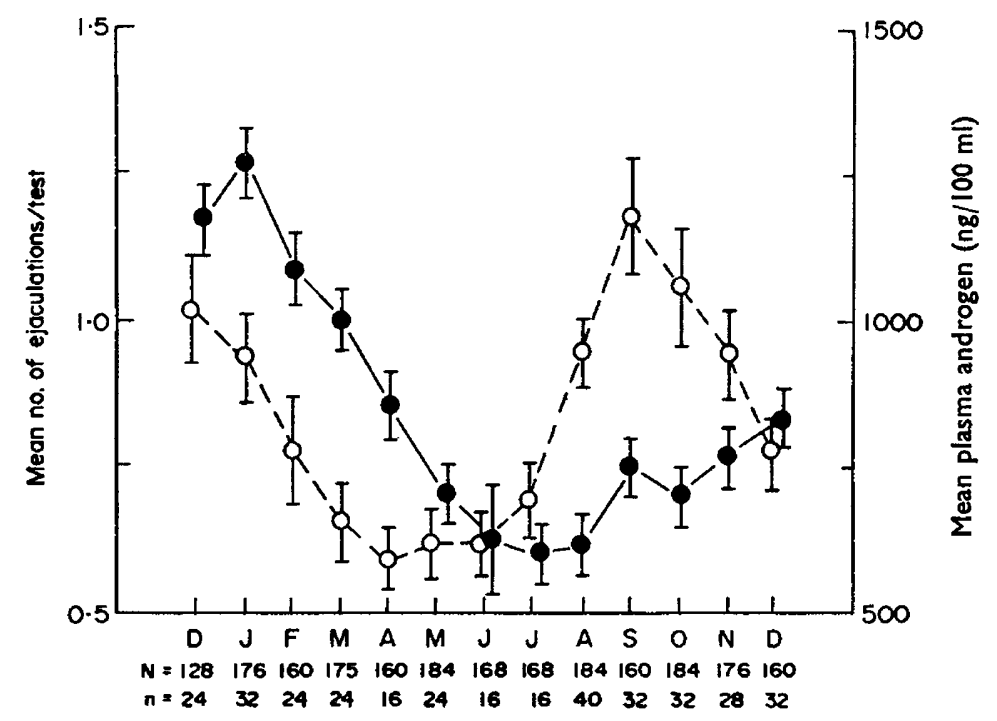

TExT-FIg. 1. Annual changes in ejaculation frequency $(\bullet)$ and in plasma androgen levels (O) of eight intact male rhesus monkeys, each paired with four ovariectomized, oestrogentreated females (32 pairs), between December 1972 and December 1973. $\mathrm{N}=$ number of tests; $\mathbf{n}=$ number of plasma samples. Vertical bars represent the S.E.M.

Text-figure 1 shows the mean numbers of ejaculations/test and the mean plasma androgen levels for all eight males. Between December and April the decline in plasma androgen was followed 4 to 8 weeks later by a corresponding decline in ejaculations. In June the curves crossed, and the increase in androgen concentrations between June and September was followed by an increase in ejaculations between July and September. This agrees with the findings of Michael \& Wilson (1974) that testosterone replacement restores ejaculation in castrated males with a lag of 4 to 6 weeks. From September onwards, however, the relation between plasma androgen and sexual potency appeared to be lost; androgen levels declined sharply while ejaculations continued to rise progressively, although they did not attain the levels of the previous winter. Data from individual males gave additional evidence for an independence of annual rhythms in plasma androgen and potency. Text-figure 2 gives data for two males, one which exhibited a marked annual plasma androgen rhythm, and one which did not, each paired with the same three females. Both males showed very clear annual changes in potency with their female partners. In Male 138, the time-course of the changes in plasma androgen suggested a 
Male 138
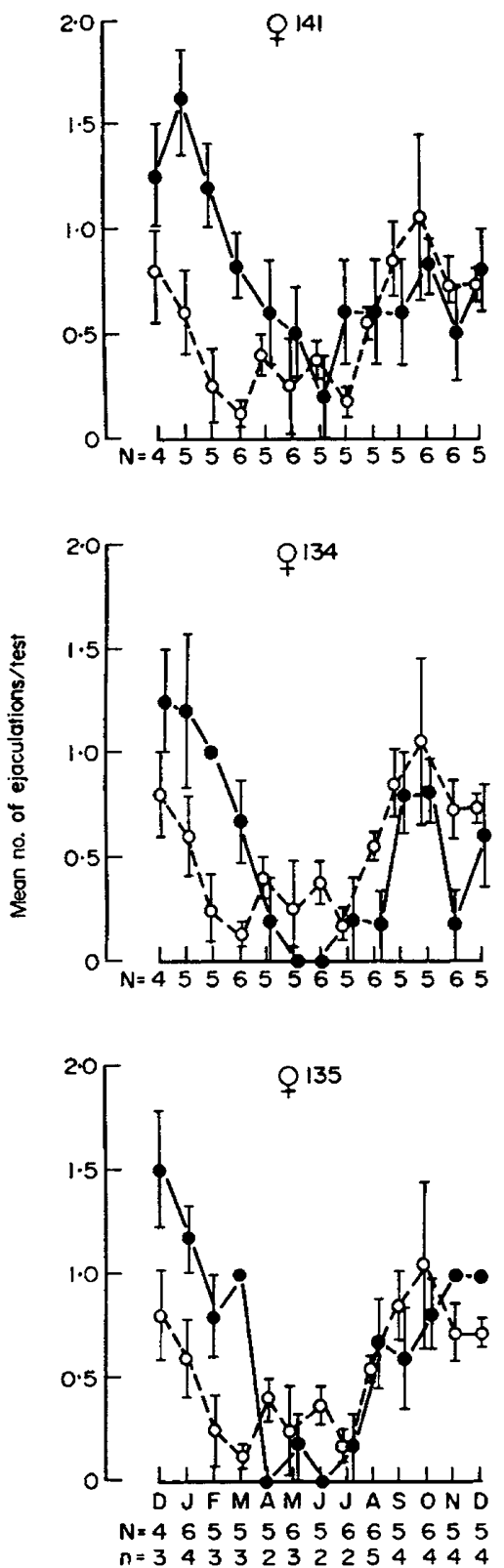

Male 144
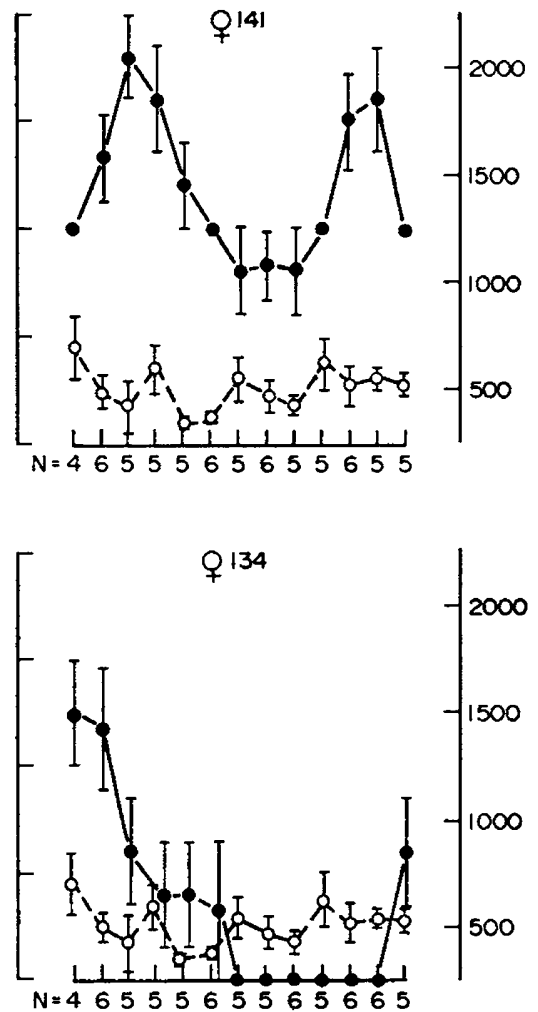

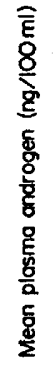

TExT-FIG. 2. Annual changes in ejaculation frequency ( $\bullet$ ) of two male rhesus monkeys each paired with the same three ovariectomized, oestrogen-treated partners. In all six pairs there were well-marked annual behavioural rhythms. Plasma androgen levels $(0)$ in Male 138 changed markedly throughout the year, but those of Male 144 did not. $\mathbf{N}=$ number of tests; $\mathbf{n}=$ number of plasma samples. Vertical bars represent the S.E.M. 
causative role, but in Male 144 it was obvious that the behavioural rhythms occurred in the absence of any significant changes in plasma androgen levels which remained rather low throughout. There were clearly individual differences in each male's behaviour when paired with different females, although the latter were ovariectomized and given daily oestrogen therapy. Comparison of the graphs showing the same female paired with different males (Text-fig. 2) indicated that the differences in the male's behaviour with different females were not due to the female alone but depended on the interactions of the pair.

These observations support those made in castrated males receiving daily exogenous testosterone in which well-marked annual rhythms of potency persisted (Michael \& Wilson, 1975). Taken together these findings suggest that long-term behavioural rhythms may occur quite independently of changes in plasma androgen and, indeed, that they may not be mediated via the gonad. The annual behavioural and endocrine rhythms occurred independently of each other in the laboratory environment of the present study in which the photoperiod was controlled, but under appropriate environmental stimulation these rhythms would be expected to be entrained to enhance the male's fertility. It is possible that the laboratory observations reflect the persistence of intrinsic rhythms which may not be maintained in the absence of changes in daylength in future years.

This investigation was supported by Public Health Service Research Grant MH 19506 from the National Institute of Mental Health. The Grant Foundation provided essential equipment.

\section{REFERENGES}

Lancaster, J.B. \& Lee, R.B. (1965) The annual reproductive cycle in monkeys and apes. In Primate Behavior, pp. 483-513. Ed. I. DeVore. Holt, Rinehart \& Winston, New York.

Michael, R.P. \& Keverne, E.B. (1971) An annual rhythm in the sexual activity of the male rhesus monkey, Macaca mulatta, in the laboratory. 7. Reprod. Fert. 25, 95-98.

Michael, R.P. \& WiLson, M.I. (1974) Effects of castration and hormone replacement in fully adult male rhesus monkeys (Macaca mulatta). Endocrinology 95, 150-159.

Michael, R.P. \& WiLson, M.I. (1975) Mating seasonality in castrated male rhesus monkeys. $\mathcal{F}$. Reprod. Fert. 43, 325-328.

Michael, R.P. \& ZuMPE, D. (1971) Patterns of reproductive behavior. In Comparative Reproduction of Nonhuman Primates, pp. 205-242. Ed. E. S. E. Hafez. Charles C. Thomas, Illinois.

Michael, R.P., SAaYman, G.S. \& Zumpe, D. (1968) The suppression of mounting behaviour and ejaculation in male rhesus monkeys (Macaca mulatta) by administration of progesterone to their female partners. F. Endocr. 41, 421-431.

Michael, R.P., Setchell, K.D.R. \& Plant, T.M. (1974) Diurnal changes in plasma testosterone and studies on plasma corticosteroids in non-anaesthetized male rhesus monkeys (Macaca mulatta). 7. Endocr. 63, 325-335.

Plant, T.M., Zumpe, D., SAUls, M. \& Michael, R.P. (1974) An annual rhythm in the plasma testosterone of adult male rhesus monkeys maintained in the laboratory. $\mathcal{F}$. Endocr. 62, 403-404.

Southwick, C.H., Beg, M.A. \& Siddigi, M.R. (1965) Rhesus monkeys in North India. In Primate Behavior, pp. 111-159. Ed. I. DeVore. Holt, Rinehart \& Winston, New York. 